\title{
Engineering and characterization of a recombinant human interferon alpha-2b fused with apolipoprotein A-I possessing prolonged action
}

\section{Pykhtina M.B. ${ }^{1,2}$, Romanov V.P. ${ }^{1,2}$, Kotlyarova A.A. ${ }^{2,3}$, Demidov E.A. ${ }^{2}$, Bannikova S.V. ${ }^{2}$, Peltek, S.E. ${ }^{2}$, Beklemishev A.B. ${ }^{1,2}$}

\begin{abstract}
Clinical use of recombinant human interferon alpha-2b (rIFN) is limited by its short half life ${ }^{1}$ and toxicity. Currently, there are two main modifications of long-acting rIFN - pegylated rIFN $^{2,3}$ and rIFN genetically fused with albumin 4 . The use of human apolipoprotein A-I (apoA-I) as a protector protein seems also promising, since apoA-I has a long half-life in the body, is not immunogenic, is capable of natural formation of lipoprotein complexes, and allows improve the pharmacokinetics of therapeutic proteins fused with it In this work, a recombinant strain of Pichia pastoris $\mathrm{X}_{33}$, producing a chimeric protein consist of rIFN, fused with human apoA-I through a flexible linker, was obtained. The IFN and apoA-I genes were optimized for expression in P. pastoris. The cultivation of a yeast strain producing a chimera was carried out in an orbital shaker. The protein yield was 30 $\mathrm{mg} / \mathrm{L}$. The chimera was purified by reverse phase chromatography and its purity was about $90 \%$. The primary structure of the chimera was confirmed by MALDI-TOF. IFN-apoA-I exhibited high specific antiviral activity comparable to that of rIFN and equal to $1.6 \times 10^{8}$ $\mathrm{IU} / \mathrm{mg}$. The chimera showed a 1.8-fold longer half-life in comparison with rIFN after a single subcutaneous injection in mice.
\end{abstract}

ResearCh StageS
1. Design and chemico-enzymatic synthesis of the genes encoding the IFN- $\alpha 2 \mathrm{~b}$ and apoA-I.
2. Construction of IFN-apoA-I chimera and its cloning in the pPICZ $\alpha \mathrm{A}$ expression vector in $E$.
coli and then in P. pastoris cells.
3. Selection of P. pastoris clones producing the highest amounts of IFN-apoA-I chimera.
4. The production of chimeric protein in flasks in an orbital shaker.
5. Isolation and purification of chimera by reversed phase chromatography.
6. Confirmation of the primary structure of the chimeric protein by mass spectrometric
analysis.
7. Antiviral activity assay of the chimeric protein.
8. Study of the pharmacokinetic properties of the chimeric protein.

\section{Results and discussion}

1. The nucleotide sequences of synthetic genes encoding human IFN- $\alpha_{2} b$ and apoA-I were designed and optimized for expression in P. pastoris cells using the following software packages: Gene designer (DNA 2.o, USA), Visual Gene Developer 1.9 and Invitrogen Gene Optimizer ${ }^{\mathrm{TM}}$. These genes were synthesized by Gen-Script and cloned into the pPICZ $\alpha$ A vecto sequentially in E. coli Topio and in P. pastoris $\mathrm{X}_{33}$ cells (Fig 1, 2). The tertiary structure of the chimeric protein was calculated using the RaptorX server application (Jinbo Xu, Senior Fellow, Computational Institute at the University of Chicago) (Fig.3).

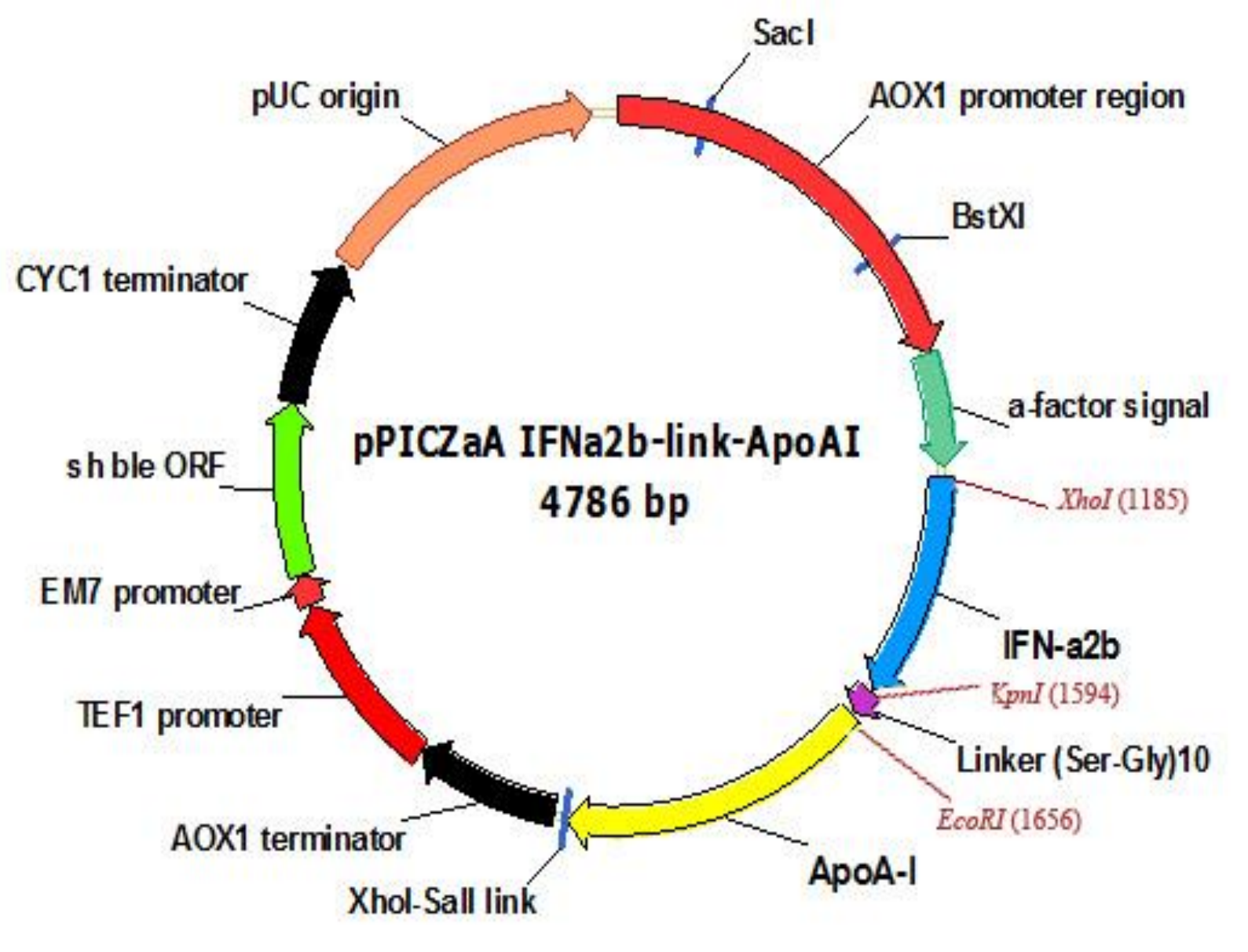

Fig. 1. Genetic map of the pPICZ $\alpha A: I F N \alpha 2 b-$ linker-ApoA-I expression vector.

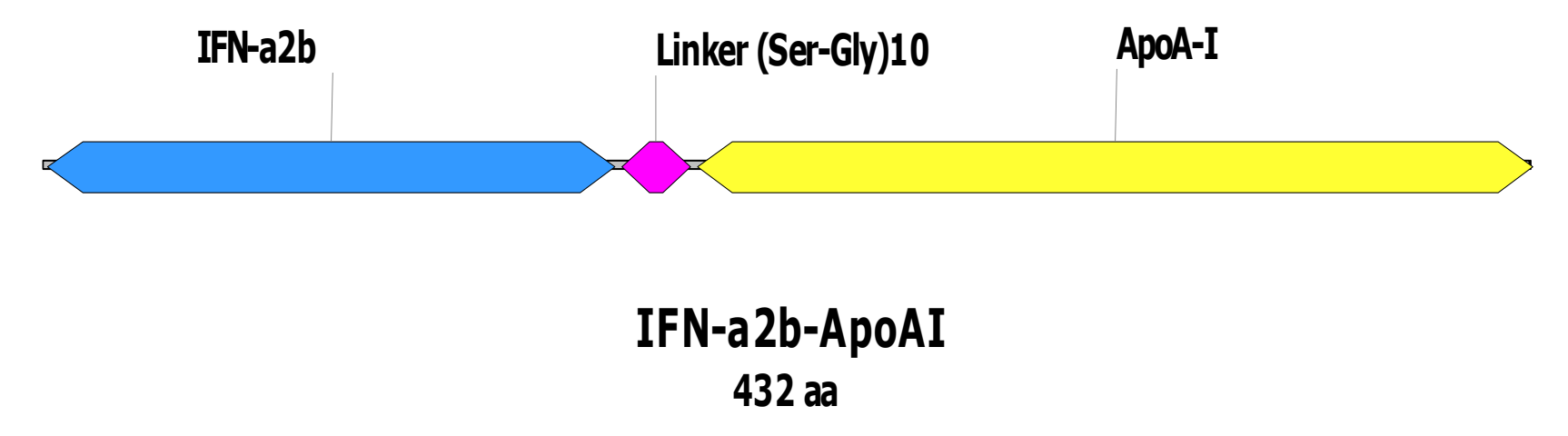

Fig. 2. Scheme of the chimeric fusion protein IFN-ApoA-I

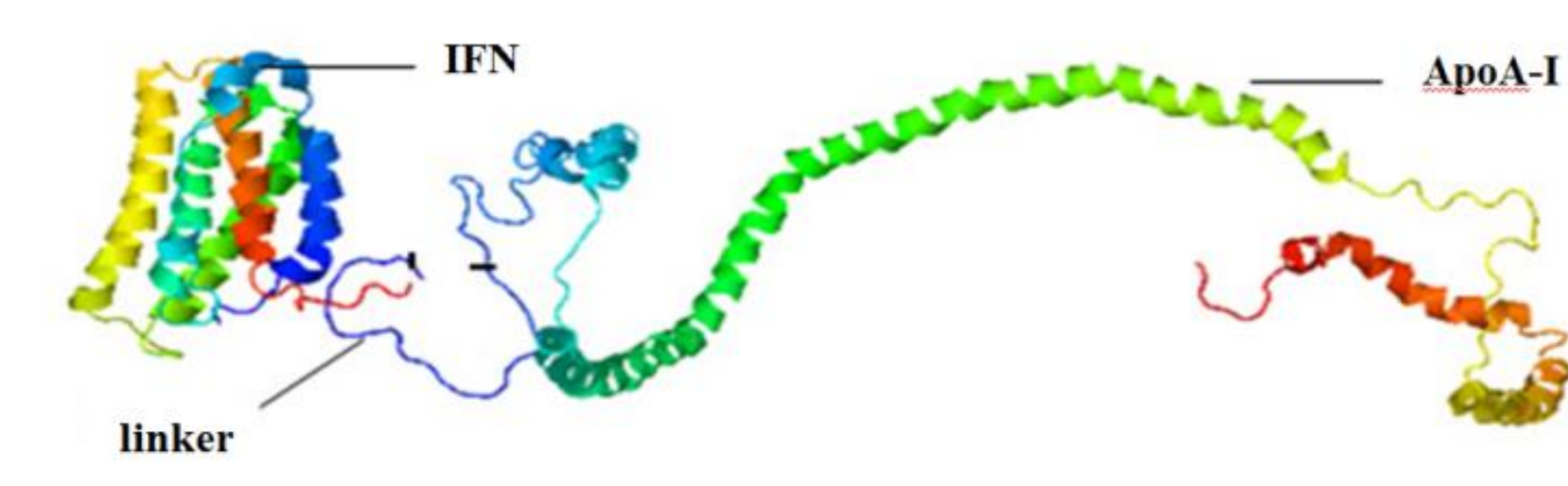

Fig. 3. Representation of the tertiary structure of the chimeric protein IFN-ApoA-I.

2. The selection of clones producing the IFN-ApoA-I chimera was performed on plates with agar medium containing $500-2000 \mu \mathrm{g} / \mathrm{ml}$ of zeocin. As a result, $P$. pastoris strains efficiently producing and secreting the IFN-ApoA-I into the culture fluid were obtained (Fig. 4).

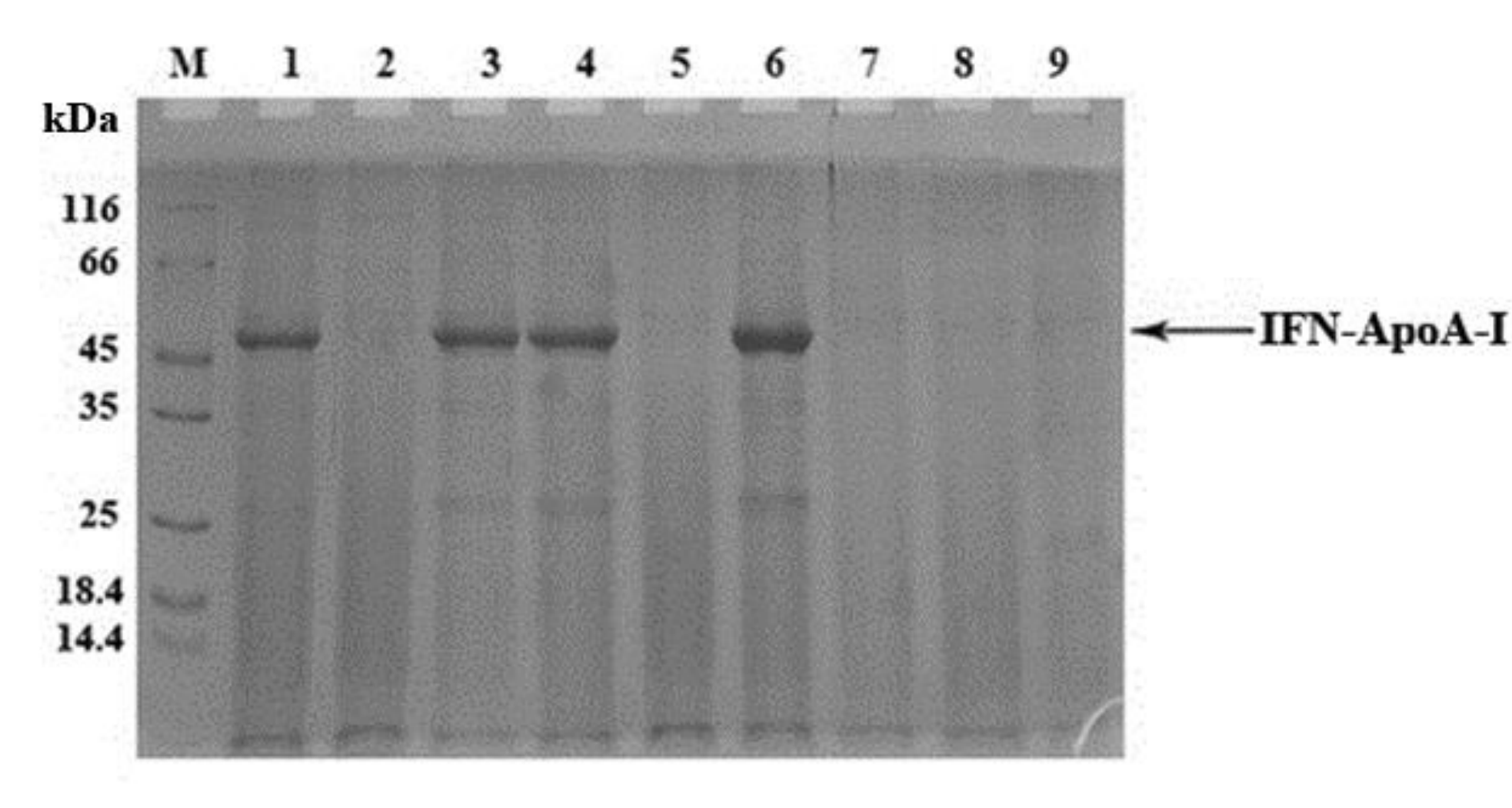

Fig. 4. SDS-PAGE analysis of TCAprecipitated proteins from the supernatants ApoA-I. Induction of expression was caried out for $96 \mathrm{~h}$ at $28^{\circ} \mathrm{C}$ using $1.0 \%(\mathrm{v} / \mathrm{v})$ methanol. Lane $\mathrm{M}$ - standard protein molecular weight marker (14-116 kDa). Lanes $1-9$ - TCA-precipitated proteins from the supernatants of nine cultured clones after 96

3. Preparative production of the chimeric cytokin was carried out by cultivating the yeast cells in conical flasks on an orbital shaker in the presence of $1.0 \%$ methanol. The yield of IFN-ApoA-I was 30 $\mathrm{mg} / \mathrm{L}$. The chimera was purified using reversedphase chromatography in acetonitrile gradient on SupelpakTM-2SV (Supelco) columns. The purity of the IFN-ApoA-I preparation was approximately 90\% (Fig. 5).

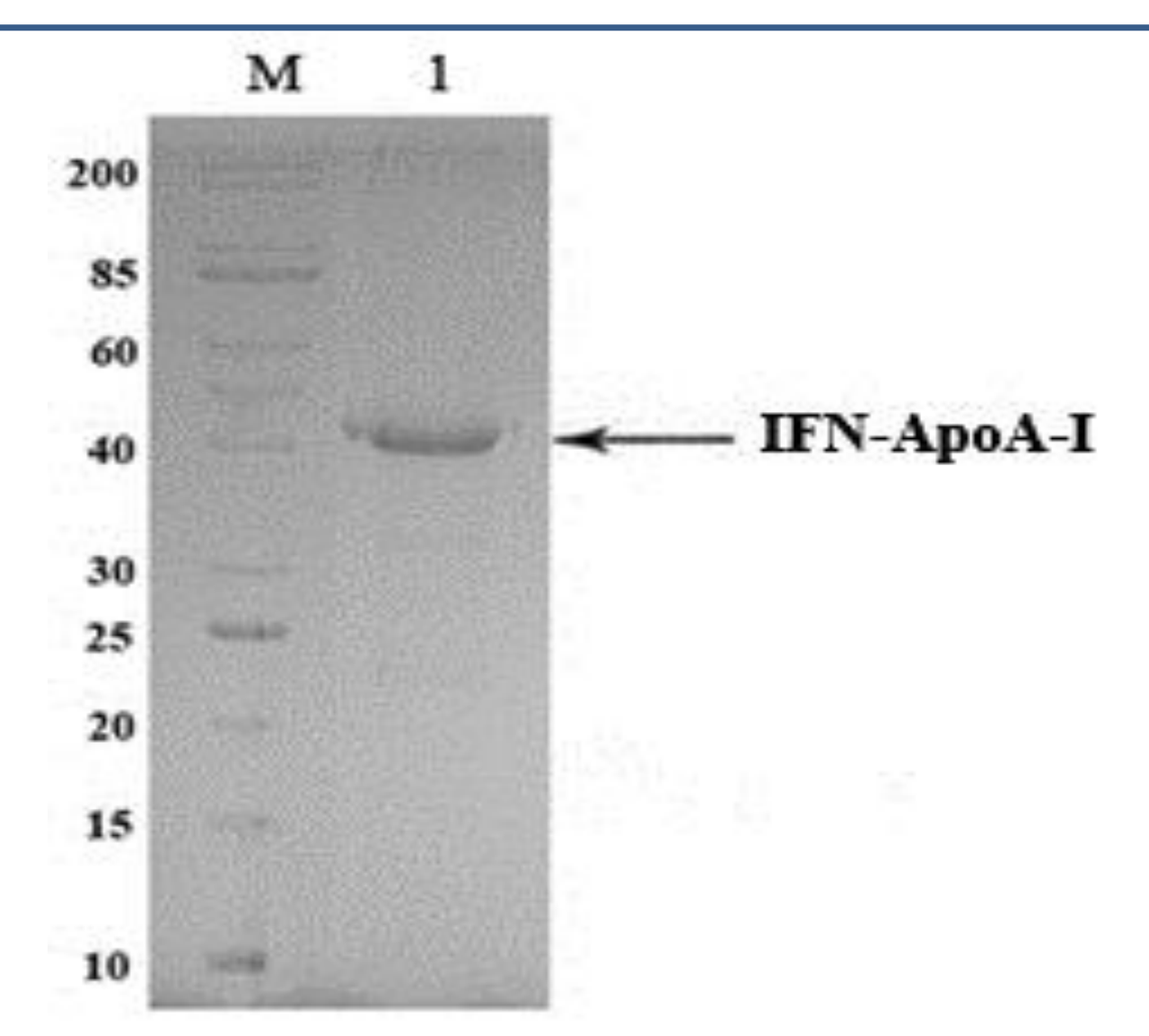

Fig. 5. SDS-PAGE analysis of chimeric protei IFN-ApoA-I that has been purified by reversed phase chromatography. Lane $\mathrm{M}$ - standard (10oo kDa) Lane 1- IFN-ApoA-1
4. The confirmation of the primary structure of the chimeric protein was carried out using MALDI-TOF Ultraflex III (Bruker, Germany). The structure of the chimeric protein was found to be as theoretically expected (Fig. 6, 7)
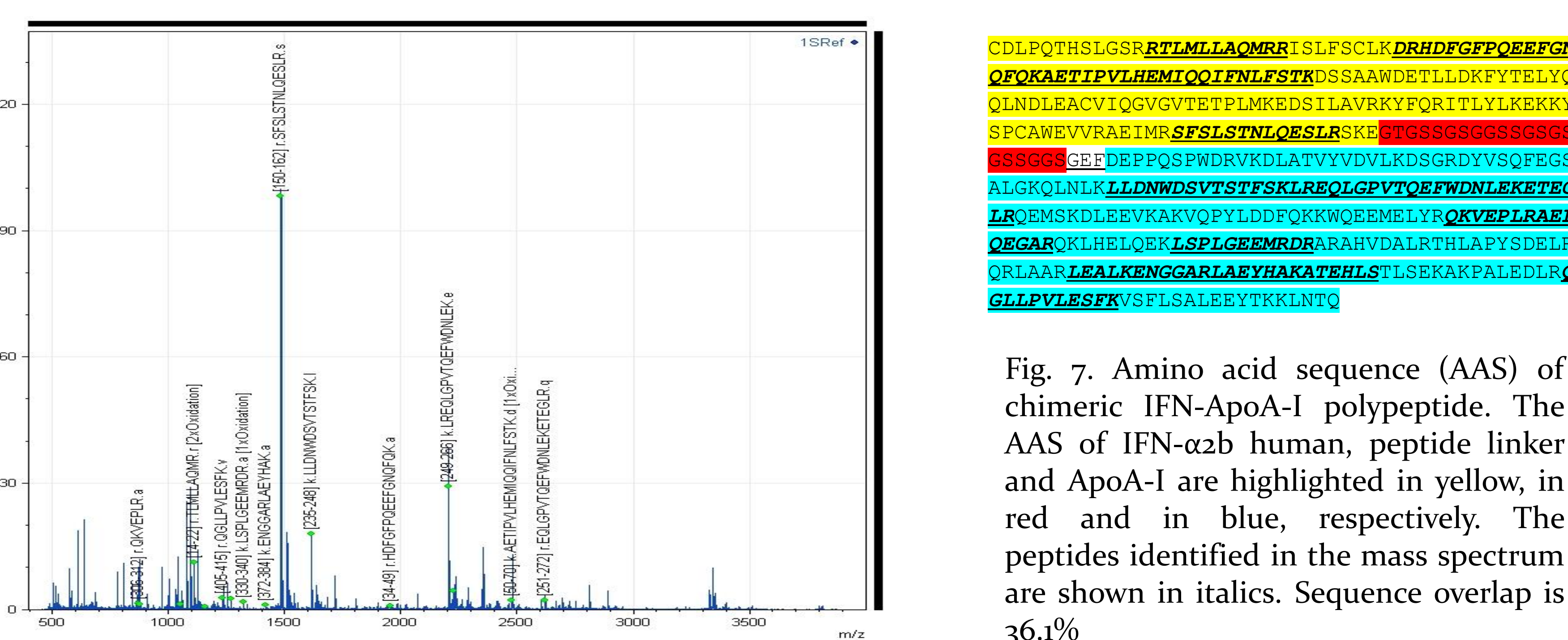
Fig. 7. Amino acid sequence (AAS) of AAS of IFN- $\alpha 2 b$ human, peptide linker and ApoA-I are highlighted in yellow, in
red and in blue, respectively. The peptides identified in the mass spectrum are shown in italics. Sequence overlap is $36.1 \%$

Fig. 6. Mass spectrum of a tryptic digest of a chimeric protein. fragments for the IFN-ApoA-I are marked.

5. The biological activity of the chimera preparation was determined by its ability to inhibit the cytopathic effect caused by equine vesicular stomatitis virus on MDBK (Madin-Darby bovine kidney) cells. IFN-ApoA-I showed a high specific antiviral activity equal to $1.6 \times 10^{8} \mathrm{IU} / \mathrm{mg}$ which corresponds to the European Pharmacopoeia standard.

6. The pharmacokinetic properties of the chimera were evaluated in comparison with the rIFN on laboratory animals. The chimera showed a 1.8-fold longer half-life in comparison with rIFN after a single subcutaneous injection of CD-1 mice male.

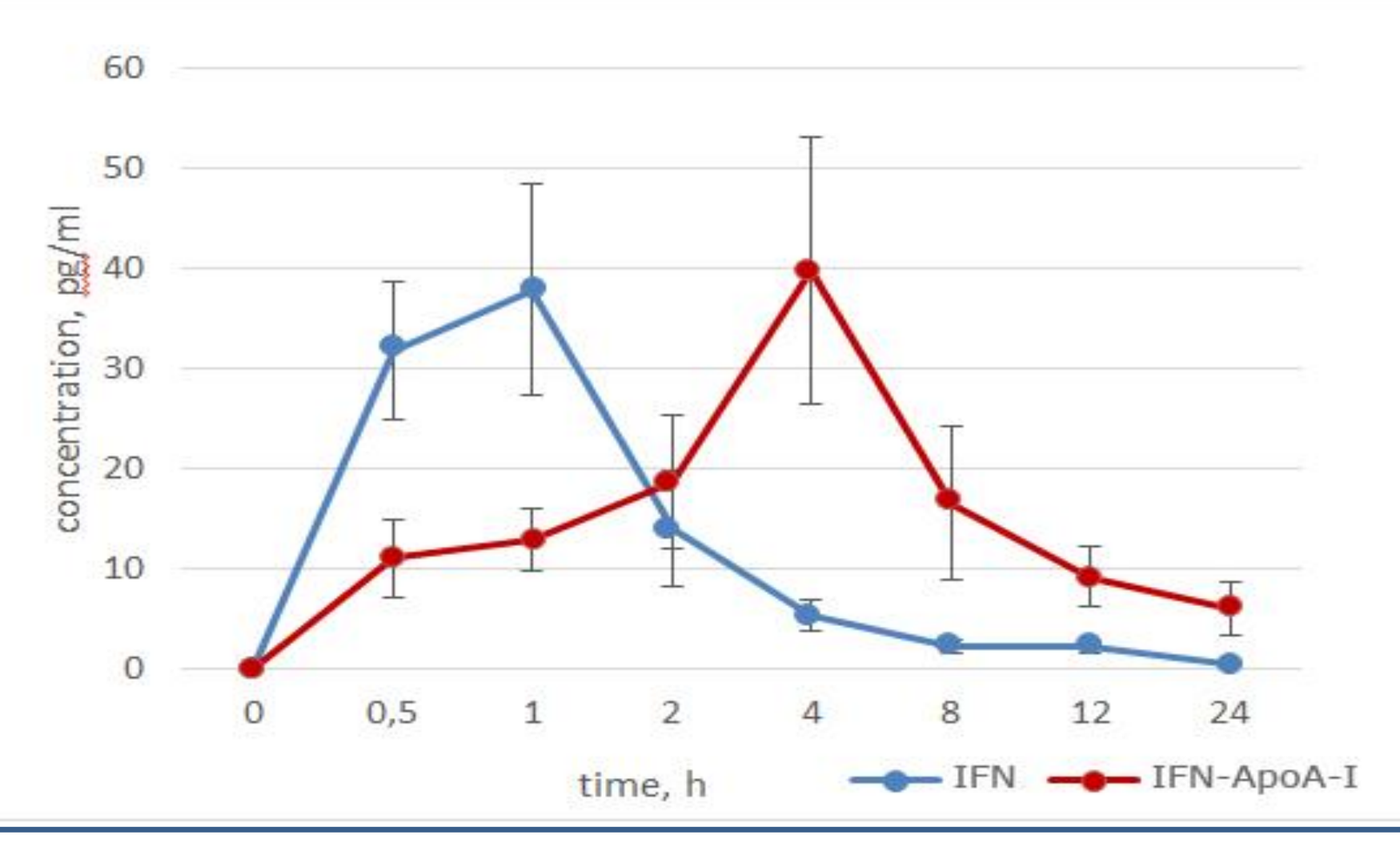

$$
\begin{aligned}
& \text { Fig. 8. Pharmacokinetic of IFN and IFN- } \\
& \text { ApoA-I in CD-1 mice male. The animals } \\
& \text { were single injected subcutaneously } \\
& \text { with equimolar amounts of rIFN and } \\
& \text { IFN-ApoA-I }-10 \mu \mathrm{g} / \mathrm{kg} \text { and } 25 \mu \mathrm{g} / \mathrm{kg} \text {, } \\
& \text { respectively. Numerical data are } \\
& \text { presented as mean } \pm \text { standard deviation } \\
& (\mathrm{n}=5)
\end{aligned}
$$

\section{Conclusion}

In this study, a recombinant Pichia pastoris $\mathrm{X}_{33}$ strain producing the chimeric IFN-ApoA-I protein was obtained. The chimera showed a high specific biological activity $\left(1.6 \times 10^{8} \mathrm{IU} / \mathrm{mg}\right)$, which is comparable to that of rIFN. The half-life of the chimeric protein was 1.8 times longer than the half-life of IFN after a single subcutaneous injection in mice.

This study suggests that ApoA-I can be used as a fusion partner to extend the half-life of a number of other recombinant therapeutically significant proteins.

\section{References}

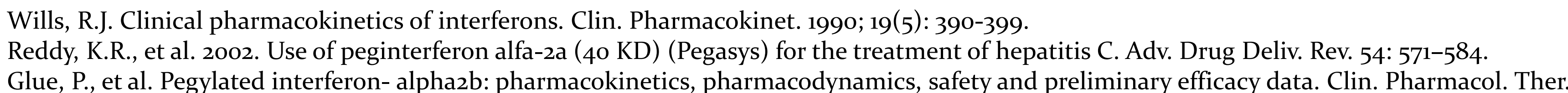
20oo; $68: 556-567$.

(1) 